\title{
USABILITY TESTING DENGAN ISO/IEC 9126-4 SISTEM INFORMASI AKADEMIK UNIVERSITAS PENDIDIKAN GANESHA DITINJAU DARI PENGGUNA DOSEN
}

\author{
Ni Wayan Erna Erawati' ${ }^{1}$ I Ketut Resika Arthana,_S.T.,M.Kom ${ }^{2}$, \\ I Made Ardwi Pradnyana, S.T.,M.T. ${ }^{3}$ \\ 1,2,3Fakultas Teknik dan Kejuruan, Universitas Pendidikan Ganesha \\ e-mail: wayanerna.erawati@gmail.com , resika@undiksha.ac.id, ardwi.pradnyana@undiksha.ac.id
}

\begin{abstract}
Abstrak
Penelitian ini dilakukan untuk menganalisis tingkat Usability pada SIAK UNDIKSHA khususnya pada SIAK Dosen. Tujuan dari analisis SIAK Dosen yaitu untuk mengetahui pengalaman pengguna dalam mengerjakan tugas-tugas yang diberikan.Metode yang digunakan dalam penelitian ini yaitu metode Usability Testing dengan menggunakan ISO/IEC 9126-4 yang memiliki tiga atribut yaitu Efektifitas, Efisien serta Kepuasan Pengguna. Untuk menentukan nilai atribut Efektifitas digunakan alat ukur Completion Rate dan Number Off Errors. Untuk menentukan nilai dari atribut Efisiensi digunakan alat ukur Overall Relative Efficiency serta menggunakan teknik Performace Measurement. Atribut Kepuasan Pengguna menggunakan alat ukur Test Lever Satisfaction dengan menggunakan teknik Concurrent Thing Aloud (CTA) dan serta menggunakan kuesioner System Usability Scale (SUS). Populasi dari penelitian ini yaitu seluruh dosen aktif UNDIKSHA. Responden dari penelitian ini berjumlah 20 responden yang digolongkan menjadi 2 kelompok yaitu kelompok responden pemula dan kelopopok responden mahir. Hasil dari penelitian ini yaitu pada atribut efektifitas diperoleh hasil $86,92 \%$ pada responden pemula dan responden mahir $86,92 \%$ yang artinya SIAK Undiksha sudah Efektif, pada atribut efisiensi diperoleh hasil pada responden pemula sebesar $87.29776 \%$ dan kelompok responden mahir yaitu sebesar $84.6087 \%$ yang artinya SIAK Undiksha sudah efisien. Pada atribut kepuasan pengguna diperoleh hasil $77.1 \%$ yang artiya responden Puas dalam mengerjakan tugas pada SIAK UNDIKSHA.
\end{abstract}

Kata Kunci : Usability Testing, Performance Measurement, Conccurrent Thing Aloud, System Usability Scale.

\begin{abstract}
This study was conducted to analyze the Usability level of SIAK UNDIKSHA especially on SIAK UNDIKSHA for the Lecturer. The purpose of analyzing SIAK UNDIKSHA for the Lecturer is to know the user experience in using this web when doing their work in this web. The method used in this study was Usability Testing methods by using ISO / IEC 9126-4 which has three attributes, there are Effectiveness, Efficiency and User Satisfaction. In order to determine the value of Effectiveness attributes the researcher used measuring tools which are Completion Rate and Number off Errors. Furthermore, in order to determine the value of Efficiency attributes the researcher used Overall Relative Efficiency and also using Performace Measurement techniques. Then, to determine the value of Satisfaction Attribute the researcher used Test Lever Satisfaction measurement tool by using Concurrent Thing Aloud (CTA) technique and also using System Usability Scale (SUS) questionnaire. The population of this study was all of active lecturers in UNDIKSHA. The total respondents of this study was 20 respondents who are classified into 2 groups, which are beginners and advances group.The result of this study showed that the attribute of effectiveness obtained $86,92 \%$ from beginner respondent and the advanced respondent obtained $86,92 \%$ which means SIAK Undiksha is Effective, the attribute of efficiency obtained $87.29776 \%$ from beginner respondent and the advanced group obtained $84.6087 \%$ which means SIAK Undiksha already efficient. The attribute of user satisfaction obtained $77.1 \%$ which means the respondents satisfied in doing their task on SIAK UNDIKSHA.
\end{abstract}

Keywords: Usability Testing, Performance Measurement, Conccurent Thing Aloud, System Usability Scale. 


\section{PENDAHULUAN}

Sistem Informasi Akademik (SIAK) merupakan suatu sistem yang dirancang dan dikembangkan sedemikian rupa dan terdiri dari sejumlah komponen seperti kurikulum, dosen, mahasiswa, silabus, $\mathrm{KRS}, \mathrm{KHS}$, nilai, dan lain sebagainya yang saling berinteraksi, saling bekerjasama membentuk suatu sistem (Ridha \& Prasetyo, 2014). Universitas Pendidikan Ganesha (Undiksha) merupakan salah satu lembaga pendidikan yang terletak di Kabupaten Buleleng. Visi Undiksha adalah menjadi perguruan tinggi pusat pengembangan pendidikan, ilmu pengetahuan, teknologi, dan seni (IPTEKS) yang berbudaya dan humanis berlandaskan Tri Hita Karana, serta menghasilkan tenaga kependidikan dan non kependidikan yang berkualitas dan berdaya saing tinggi (Universitas Pendidikan, 2017). SIAK Undiksha mempunyai 3 pengguna yaitu mahasiswa, pegawai dan dosen. Bagi pengguna mahasiswa, SIAK Undiksha dapat digunakan untuk menyusun Kartu Rencana Studi (KRS), mencetak Kartu Hasil Studi (KHS), mencetak Kartu Daftar Nilai (KDN), dan lain-lainnya. Bagi pengguna pegawai, SIAK Undiksha digunakan untuk menginputkan atau mendapatkan data sesuai kebutuhan fakultas atau universitas. Bagi pengguna dosen, SIAK Undiksha digunakan untuk melihat daftar peserta kuliah, mengunggah daftar peserta kuliah, melihat jadwal mengajar, mengunggah kontrak, silabus, RPS, menginputkan nilai mahasiswa, dan lain lain. Untuk mengetahui respon awal pengguna terhadap SIAK Undiksha, peneliti melakukan wawancara awal dengan dua orang dosen yang berbeda jurusan. Alasan peneliti mengambil responden dari jurusan yang berbeda yaitu pertama jurusan Pendidikan Teknik Informatika dari Fakultas Teknik Dan Kejuruan sebagai responden mahir, karena jurusan Pendidikan Teknik Informatika merupakan jurusan dengan program study yang paling dekat dengan sistem informasi yaitu salah satunya website dan sistem. Untuk responden kedua yaitu sebagai reponden pemula, peneliti mencari secara acak di luar Fakultas Teknik Dan Kejuruan karena fakultas lain tidak memiliki jurusan dengan program study yang mempelajari tentang website dan sistem.

Berdasarkan hasil wawancara dengan Ibu Dr. Ketut Agustini, S.Si.,M.Si selaku dosen di Jurusan Pendidikan Teknik Informatika mengatakan bahwa peranan dari SIAK dosen sangatlah penting, terutama dalam pemberian nilai hasil belajar mahasiswa setiap semesternya, dalam penggunaan SIAK tidak menemukan masalah untuk mengakses setiap menunya. Kemudian SIAK sangat mempermudah pekerjaan beliau khususnya dalam proses administrasi perkuliahan misalnya saat penginputan nilai mahasiswa. Namun dalam proses validasi nilai setiap mahasiswa beliau mengatakan masih kurang paham dengan prosesnya.

Berdasarkan hasil wawancara dengan Bapak Drs. I Nyoman Murda, M. Pd selaku dosen Jurusan Pendidikan Guru Sekolah Dasar mengatakan SIAK dapat membantu para dosen dalam melakukan proses penilaian pada saat akhir semester. Namun saat penginputan nilai hasil belajar, beliau masih belum memahami cara menggunakan SIAK tersebut, sehingga masih meminta bantuan kepada orang lain. Beliau pernah mengikuti pelatihan cara menggunakan SIAK, akan tetapi beliau belum bisa memahami cara menggunakan SIAK.

Sebelumnya telah dilakukan penelitian SIAK dosen oleh $\mathrm{Ni}$ Wayan Swandari dengan judul "Survei Deskriptif Penerimaan Sistem Informasi Akademik (Siak) Pada Dosen Universitas Pendidikan Ganesha", Penelitian ini melibatkan 208 responden. Hasil dari penelitian ini yaitu sebesar $91 \%$ penerimaan SIAK dosen Undiksha maka dikategorikan sangat tinggi. Dari hasil penelitian diatas maka peneliti ingin melakukan penelitian dengan study kasus yang sama yaitu SIAK dosen Undiksha. Penelitian yang akan dilakukan peneliti saat inj yaitu melakukan pengujian usability pada SIAK dosen undiksha guna 
mengetahui kenyaman serta kemudahan responden saat menggunakan SIAK (Swandari, Arthana, \& Darmawiguna, 2018).

Usability merupakan pengalaman pengguna ketika mengunakan atau berinteraksi dengan sebuah system atau website (Gatsou, Politis, \& Zevgolis, 2013). Human Computer Interaction merupakan sebuah ilmu yang mempelajari tentang desain, evaluasi serta implementasi dari sebuah interaksi sistem atau website yan digunakan (Saifulloh \& Asnawi, 2015). Dengan demikian, untuk membuat sebuah aplikasi dengan memperhatikan aspek usability seperti efektivitas, efisiensi, dan memuaskan pengguna merupakan kunci keberhasilan website dan syarat penerimaan pengguna terhadap sebuah website. Metode yang digunakan dalam penelitian ini yaitu metode Usability Testing yang merujuk pada ISO/IEC 9126-4 Metrics dengan menggunakan atribut efektifitas, efisien, serta kepuasan. Alasan menggunakan ISO/IEC 9126-4 yaitu karena memiliki tiga atribut yang digunakan untuk melakukan pengujian usability yaitu efektifitas, efisien, serta kepuasan. Ketiga atribut tersebut digunakan oleh peneliti dalam melakukan penelitian SIAK dosen Undiksha pada aspek Usability untuk mengalisis kemudahan dalam menggunakan SIAK dosen. Alat ukur yang digunakan yaitu complete rate, number of errors, overall relative efficiency, test level satisfaction dengan menggunakan teknik performance measurement, CTA (Concurrent Thing Aloud), dan kuesioner SUS (System Usability Scale). Teknik Performace Measurement ini berupa tingkat kecepatan responden pada saat mengerjakan task yang diberikan oleh peneliti, hasil dari teknik ini akan diolah menjadi data kuantatif. Sedangkan hasil dari teknik CTA ini yaitu dalam bentuk kata-kata verbal yang diungkapkan oleh responden yang nantinya akan diubah menjadi data kualitatif sekaligus menjadi acuan peneliti untuk menyusun rekomendasi perbaikan untuk halaman SIAK Undiksha, sedangkan kuesioner SUS ini digunakan untuk mengeksplorasi pengalaman pengguna ketika berinteraksi dengan aplikasi yan menghasilkan data kuantitatif.

Teknologi informasi, terutama pada penggunaan sistem informasi, sudah banyak dimanfaatkan dalam kehidupan sehari-hari, tetapi tidak semua sistem informasi pernah melalui tahap pengujian usability. Hal ini disebabkan oleh fokus permasalahan yang masih terpusat pada pengelolaan kebutuhan, jadwal, dan sumber daya yang tersedia untuk implementasi sistem tersebut. Sedangkan pengukuran usability sistem dari sudut pengguna masih dianggap bukan kebutuhan utama dalam pengembangan sebuah sistem, sehingga sangat jarang dilakukan. Agar mengetahui hasil yang telah dicapai atau kemampuan pengguna perlu diadakan sebuah pengukuran terhadap keberhasilan sistem agar pengunaan sebuah system dapat terpenuhi. Untuk mendapatkan data atau hasil yang akurat maka dilihat dari pengukuran yang dilakukan dengan mengunakan 3 atribut yaitu efektifitas, efisiensi, serta kepuasan pengguna dalam menggunakan sebuah system (Sahfitri, Ulfa, Maria, \& Darma, 2002).

Bertitik tolak dari uraian di atas dipandang perlu dilakukannya suatu penelitian tentang analisa usability pada SIAK Undiksha untuk dapat mengetahui tingkat kenyamanan serta kemudahan pengguna saat menggunakan SIAK, maka dari itu peneliti melakukan penelitian yang berjudul "Usability Testing Dengan Iso/lec 9126-4 Sistem Informasi Akademik Universitas Pendidikan Ganesha Ditinjau Dari Pengguna Dosen".

\section{METODE}

Menurut ISO/IEC 9126-4 Metrics mengatakan bahwa dalam melakukan usability testing terdapat tiga atribut yang digunakan dalam proses pengujian sebuah sistem yaitu (Mifsud, 2015):

Efektivitas merupakan Keakuratan dan kelengkapan pengguna mencapai tujuan tertentu. Dalam atribut efektifitas terdapat dua alat hitung yang digunakan untuk mendapatkan data kuantitatif. Dua alat hitung dalam atribut efektifitas yaitu :Completion Rate merupakan Efektivitas dapat dihitung dengan mengukur tingkat 
penyelesaian (completion rate). Tingkat penyelesaian (completion rate) adalah metrik yang sangat mudah dimengerti sudah banyak digunakan (Sauro \& Lewis, 2009).Number Of Errors yaitu Pengukuran lain melibatkan penghitungan jumlah kesalahan yang dilakukan peserta saat mencoba menyelesaikan sebuah tugas. Kesalahan dapat berupa tindakan, kesalahan, atau kelalaian yang tidak diinginkan yang dilakukan pengguna saat mencoba melakukan tugas. Sebaiknya menetapkan deskripsi singkat, tingkat keparahan dan mengklasifikasikan setiap kesalahan di bawah kategori masingmasing. Meski bisa memakan waktu, menghitung jumlah kesalahan memang memberikan informasi diagnostik yang sangat baik. Tingkat penyelesaian dihitung dengan menetapkan nilai biner ' 1 ' jika peserta uji berhasil menyelesaikan tugas dan '0' jika dia tidak melakukannyaBerdasarkan analisis terhadap 719 tugas yang dilakukan dengan menggunakan perangkat lunak konsumen dan bisnis, Jeff Sauro menyimpulkan bahwa rata-rata jumlah kesalahan per tugas adalah 0,7, dengan 2 dari setiap 3 pengguna melakukan kesalahan. Hanya $10 \%$ dari tugas yang diamati dilakukan tanpa kesalahan, sehingga mengarah pada kesimpulan bahwa sangat normal bagi pengguna untuk membuat kesalahan saat melakukan tugas (Sauro \& Lewis, 2009). Efisiensi merupakan Sumber daya yang dikeluarkan terkait dengan keakuratan dan kelengkapan pengguna mencapai tujuan. Efisiensi kemudian dapat dihitung dengan salah satu dari 2 cara berikut:Time-Based Efficiency merupakan Efisiensi berbasis waktu menggunakan rasio waktu yang dibutuhkan oleh pengguna yang berhasil menyelesaikan tugas sehubungan dengan total waktu yang diambil oleh semua pengguna per task. Overall Relative Efficiency yaitu Efisiensi relatif keseluruhan menggunakan rasio waktu yang dibutuhkan oleh pengguna yang berhasil menyelesaikan tugas sehubungan dengan total waktu yang diambil oleh semua pengguna.
Selain menggunakan alat ukur time-based efficiency dan overall relative efficiency menurut iso/iec 9126-4 metrics teknik yang dapat digunakan untuk mendapatkan data yang lebih spesifik yaitu dengan menggunakan teknik performance measurement. Dalam usabilityhome.com (Anonim, n.d.) disebutkan "This technique is to used to obtain quantitative data about test participants' performance when they perform the tasks during usability test. This will generally prohibit an interaction between the participant and the tester during the test that will affect the quantitative performance data. The technique can be used in combination with retrospective testing, post-test interview or questionnaires so that both quantitative and qualitative data are obtained. The technique can be used in the following development stages: code, test, and deployment." Teknik ini dapat digunakan pada tahap pembangunan sebagai berikut: kode, pengujian, dan penyebaran. Dalam teknik performance measurement ini diukur waktu yang digunakan oleh responden dalam mengerjakan suatu tes yang diberikan oleh peneliti. Teknik ini biasanya menggunakan alat stopwatch untuk mengukur waktu pengerjaan tes.

Kepuasan yaitu terdapat dua cara yag digunakan dalam menganalisis kepuasan pengguna saat mengguna suatu aplikasi atau website yaitu :Task-Level Satisfaction yaitu setelah pengguna mengerjakan task skenario (terlepas dari berhasil atau tidaknya mencapai tujuan), pengguna harus diberikan kuesioner sehingga dapat mengukur seberapa sulit task skenario yang diberikan. Biasanya terdiri dari hingga 5 pertanyaan, kuesioner post-task ini sering berbentuk skala Likert dan tujuannya adalah untuk memberikan wawasan tentang kesulitan tugas seperti yang terlihat dari perspektif pengguna.Kuesioner post-test yang paling popular digunakan :ASQ (After Scenario Questionnaire), NASA-TLX (NASA's task load index is a measure of mental effort), SMEQ (Subjective Mental Effort Questionnaire), UME (Usability Magnitude Estimation), SEQ (Single Ease Question) 
Test-Level Satisfaction merupakan tingkat Kepuasan Uji diukur dengan memberikan kuesioner kepada setiap peserta tes pada akhir pengerjaan tas skenario usablity testing. Ini berfungsi untuk mengukur kesan mereka terhadap keseluruhan kemudahan penggunaan sistem yang sedang diuji. Kesioner yang paling popular digunakan : SUS (System Usability Scale),SUPR-Q (Standardized User Experience Percentile Rank Questionnaire), CSUQ (Computer System Usability Questionnaire), QUIS (Questionnaire For User Interaction Satisfaction), SUMI (Software Usability Measurement Inventory)

Kuesioner yang dipilih untuk melakukan evaluasi usability testing dipilih berdasarkan dua hal yaitu berdasarkan alokasi anggaran biaya dan pentingnya kepuasan pengguna. Sangat di rekomendasikan SUMI digunakan jika ada cukup anggaran yang dialokasikan dan kepuasan pengguna sangat penting. Jika pengukuran kepuasan pengguna itu penting namun tidak ada anggaran alokasi yang besar, maka orang harus menggunakan SUS (Garcia, 2013). Di sisi lain, Sauro merekomendasikan penggunaan SUS untuk mengukur kepuasan pengguna terhadap perangkat lunak, perangkat keras dan perangkat mobile sedangkan SUPR-Q harus digunakan untuk mengukur tingkat kepuasan uji situs web. SUS juga disukai karena telah ditemukan memberikan hasil yang sangat akurat. Selain itu, ini terdiri dari skala yang sangat mudah yang mudah diberikan kepada peserta, sehingga membuatnya ideal untuk penggunaan dengan ukuran sampel yang kecil (Sauro, 2011).

Menurut Nielsen (dalam Ersa 2015) jumlah yang disarankan dalam melakukan pengumpulan data secara kuantitatif adalah 20 responden. Namun, untuk menghasilkan jumlah error $\pm 10 \%$, maka jumlah responden yang disarankan adalah 71 responden.

Selain penggunaan kuesioner dalam mengukur kepuasan pengguna, pengujian Usability testing juga membutuhkan alat ukur lain yang digunakan untuk mendapatkan rekomendasi perbaikan sistem yaitu dengan menggunaka teknik Thing Aloud. Berpikir-keras (Thing Aloud) adalah metode yang digunakan secara luas untuk pengujian kegunaan perangkat lunak, antarmuka, website, dan (instruksional) dokumen. Prinsip dasar dari metode ini adalah bahwa pengguna yang berpotensi diminta untuk menyelesaikan serangkaian tugas dengan skenario yang diberikan, dan untuk terus mengungkapkan pikiran mereka saat mengerjakan tugas-tugas (Az-zahra, Pinandito, \& Tolle, 2015). Metode ini memungkinkan evaluator untuk memahami bagaimana pengguna berinteraksi dengan interface, dan apa pertimbangan pengguna selanjutnya dalam pikiran ketika menggunakan interface. Jika pengguna menyatakan bahwa urutan langkah-langkah yang dilakukan pada produk untuk mencapai tujuan tugas mereka berbeda dari apa yang mereka harapkan, mungkin interface berbelit-belit. CTA adalah teknik evaluasi think aloud yang dilakukan ketika responden sedang berinteraksi dengan objek. RTA dilakukan ketika responden selesai melakukan interaksi dengan objek sehingga responden menceritakan apa yang dipikirkan (Think Aloud) saat berinteraksi dengan objek tersebut dengan menggunakan alat bantu media video audio yang memutarkan kembali aktivitas yang dilakukan responden selama berinteraksi dengan objek (Utama, 2011). Teknik ini dapat dibedakan menjadi 2 yaitu CTA (Concurrent Think Aloud) dan RTA (Retrospective Think Aloud). Dalam sebuah penelitian berjudul "The value of Retrospective and Concurrent Think Aloud in formative usability testing of a physician data query tool" yang membandingkan kedua metode tersebut yaitu (Peute, de Keizer, \& Jaspers, 2015) :

a. CTA dilakukan secara signifikan lebih baik daripada RTA dalam mendeteksi masalah kegunaan. Pengujian usability dengan mengguakan teknik CTA yaitu subyek diinstruksikan untuk verbalisasi pikiran mereka secara bersamaan melakukan tugas-tugas yang telah ditetapkan dalam sistem. Verbalisasi yang dihasilkan dianggap 
mengungkapkan isi memori kerja subjek. Dalam CTA proses berpikir diekspresikan selama kinerja tugas. Subjek diinstruksikan untuk berpikir keras saat melakukan task skenario usability testing. Sejalan dengan prosedur Think Aloud peneliti yang menyertainya (fasilitator) tidak akan mengganggu sesi dengan memberikan bantuan. Fasilitator akan mengingatkan subjek untuk terus berpikir keras jika subjek harus terdiam. CTA menunjukkan sensitivitas yang lebih tinggi untuk masalah kegunaan yang berkaitan dengan grafis / simbol, masalah navigasi, pesan kesalahan, dan tata letak dan organisasi informasi pada interface. Secara keseluruhan, protokol verbal CTA mengandung jumlah verbalisasi yang lebih tinggi, memberikan lebih banyak wawasan tentang masalah kegunaan yang terdeteksi, dan memberikan lebih banyak verbalisasi pada kinerja tugas langsung dibandingkan dengan protokol RTA. CTA menginstruksikan membangkitkan subjek untuk mengungkapkan pemikiran ingatan jangka pendek tugas mereka. Selama CTA, protokol verbal mencerminkan pemikiran jangka pendek pada kinerja tugas, sehingga mengarah pada keefektifan CTA yang lebih tinggi dalam mendeteksi masalah kegunaan yang terkait dengan kinerja tugas pengguna langsung.

b. RTA menjelaskan masalah usability yang unik dan kebutuhan pengguna baru. Dalam kondisi RTA, subyek menerima tugas pengujian kegunaan yang sama dalam bentuk skenario. Mereka diperintahkan untuk melaksanakan task skenario usability testing tanpa bantuan dari dari peneliti. Setelah task selesai dikerjakan, kondisi uji dihentikan. Selanjutnya, subjek diminta untuk verbalisasi pikiran mereka secara retrospektif saat melihat rekaman video dari tindakan mereka dalam sistem. Dalam melakukannya, mereka mengungkapkan yang mereka rasakan pada saat mengerjakan task skenario.
Subyek mampu menghentikan sebentar perekaman ketika mereka merasa perlu untuk menjelaskan secara rinci tindakan yang dipandang sebagai prosedur RTA dan jeda ini termasuk dalam waktu direkam untuk pengukuran tugas. RTA menawarkan wawasan tentang fungsionalitas sistem baru. Selama verbalisasi retrospektif subjek bisa menghentikan rekaman untuk mengungkapkan pikirannya secara verbal yang berpotensi mengarah pada waktu yang lebih lama pada verbalisasi retrospektif daripada kinerja tugas sebenarnya.

\section{HASIL DAN PEMBAHASAN}

Pada bagian ini analisis data yang didapat dari proses usability testing dengan menggunakan ISO/IEC 9126-4 terdapat tiga atribut yaitu efektifitas, efisiensi, dan kepusan pengguna. Alat ukur yang digunakan unutk memperoleh hasil ketiga atribut tersebut yaitu Completion Rate, Number Of Errors, Overall Relatif Efficiency, Performance Measurement, Conccurrent Thing Aloud dan kuesioner System Usability Scale (SUS).

\section{Efektivitas}

Berdasarkan analisis yang telah dilakukan bahwa dari pengolahan data menggunakan alat ukur Completion Rate hasil yang diperoleh yaitu sebesar $86.92 \%$ pada responden pemula dan $86.92 \%$ pada responden mahir yang artinya SIAK Dosen Undiksha sudah sangat membantu responden dalam menyelesaikan tugastugas sedangkan menggunakan alat ukur Number Of Errors diperoleh sebesar 13\% pada responden pemula dan $13 \%$ pada responden mahir yang artinya kesalahan yang dilakukan oleh responden pada saat menyelesaikan tugas sangat kecil, jadi dapat dikatakan jika SIAK Dosen Undiksha tersebut sudah efektif.

\section{Efisiensi}

Berdasarkan hasil perhitungan yang telah dilakukan yaitu kelompok responden pemula menempuh waktu dan keberhasilan tugas rata-rata sebesar $87.29776 \%$ dan kelompok responden 
mahir yaitu sebesar $84.6087 \%$. rata-rata pengerjaan maka diatas yang pertama yaitu overall Relative Efficiency tidak adanya perbedaan waktu yang signifikan dari kelompok responden pemula dan responden mahir dengan presentase kelompok pemula yaitu $82.61 \%$ sedangkan kelompok responden mahir yaitu $86.65 \%$. perhitungan yang kedua yaitu dengan membuat kesimpulan secara statistic mengunakan Mann Whitney $U$ Test dari 13 tugas yang diberikan dapat dinyatakan bahwa tidak ada perbedaan yang signifikan pada waktu pengerjaan tugas responden kelompok pemula dan kelompok mahir. Dari kesimpulan diatas dapat ditarik kesimpulan bahwa SIAK undiksha yang ditinjau dari pengguna dosen sudah efisien.

\section{Kepuasan Pengguna}

Kesimpulan yang didapatkan dari pengujian Usability Testing pada SIAK dosen Undiksha, diketahui bahwa responden puas menggunakan SIAK dosen tersebut yang terdapat pada hasil kuesioner SUS yaitu 77.1.
Namun dari hasil teknik Conccurrent Thing Aloud masih ada responden yang tidak mengetahui letak dari beberapa submenu yang disediakan dalam website tersebut alasannya karena terlalu banyak terdapat sub-sub menu didalam menu utama, seperti mencari sub-submenu yang terdapat pada menu akademik yaitu menu daftar peserta kuliah, jadwal (per bulan, per minggu, dan perhari), mencari sub menu yang ada pada agenda mengajar dosen (seperti submenu silabus, submenu mengisi agenda mengajar dosen), menu nilai mahasiswa (seperti mencetak DPNA mahasiswa serta menginputkan nilai mahasiswa).

Rekomendasi perbaikan akan dilakukan dengan membuat wireframe, dimana latar belakang yang digunakan dalam perbaikan ini adalah dari hasil teknik Conccurrent Thing Aloud dengan menggunakan dasar teori $\mathrm{HCl}$, Delapan Aturan Emas Desain Antar Muka Pengguna(Golden Rules Of User) oleh Ben Shneiderman dan Don't Make Me Thing oleh Stave Krug.

Tabel 1. Kesimpulan Kesulitan/Masalah Yang Dialami Responden

\begin{tabular}{|c|c|c|c|}
\hline No & $\begin{array}{l}\text { Kesulitan Masalah } \\
\text { Yang Dialami }\end{array}$ & $\begin{array}{c}\text { Fitur } \\
\text { Akademik }\end{array}$ & Kode Resp. \\
\hline 1 & $\begin{array}{l}\text { Kesusahan pada saat } \\
\text { mengunduh daftar } \\
\text { peserta kuliah. }\end{array}$ & $\begin{array}{l}\text { Daftar } \\
\text { Peserta } \\
\text { Kuliah }\end{array}$ & RUP003 \\
\hline 2 & $\begin{array}{l}\text { Kesusahan pada saat } \\
\text { mencari menu jadwal } \\
\text { mengajar perhari. }\end{array}$ & Jadwal & $\begin{array}{l}\text { RUP004,RUP007,RUP011,RUP014, } \\
\text { RUP019. }\end{array}$ \\
\hline 3 & $\begin{array}{l}\text { Kesusahan pada saat } \\
\text { mengisikan agenda } \\
\text { mengajar dosen karena } \\
\text { biasanya dosen mengisi } \\
\text { agenda mengajar di } \\
\text { buku/catatan yang } \\
\text { diberikan oleh fakultas } \\
\text { masing-masing. }\end{array}$ & $\begin{array}{l}\text { Agenda } \\
\text { Mengajar }\end{array}$ & $\begin{array}{c}\text { RUP003,RUP007,RUP009,RUP010, } \\
\text { RUP011,RUP012,RUM005,RUM006, } \\
\text { RUM013. }\end{array}$ \\
\hline 4 & $\begin{array}{lr}\text { Kesulitan pada saat } \\
\text { mencari dan mengunduh } \\
\text { silabus, } & \text { karena } \\
\text { responden } & \text { sudah } \\
\text { mendapatkan } & \text { silabus } \\
\text { dari jurusan } & \text { masing- }\end{array}$ & Silabus & $\begin{array}{l}\text { RUP001,RUP003,RUP004,RUM002, } \\
\text { RUM005,RUM006,RUM013,RUM016. }\end{array}$ \\
\hline
\end{tabular}




\begin{tabular}{|c|l|c|c|}
\hline No & \multicolumn{1}{|c|}{$\begin{array}{c}\text { Kesulitan Masalah } \\
\text { Yang Dialami }\end{array}$} & $\begin{array}{c}\text { Fitur } \\
\text { Akademik }\end{array}$ & Kode Resp. \\
\hline masing & RUP001 \\
\hline 5 & $\begin{array}{l}\text { Kesulitan mencari menu } \\
\text { nilai mahasiswa karena } \\
\text { biasanya meminta } \\
\text { bantuan pada orang lain. }\end{array}$ & $\begin{array}{c}\text { Nilai } \\
\text { Mahasiswa }\end{array}$ & RUP007 \\
\hline 6 & $\begin{array}{l}\text { Kesusahan pada saat } \\
\text { melakukan Cetak DPNA } \\
\text { karena biasanya sudah } \\
\text { diberikan oleh petugas. }\end{array}$ & Cetak DPNA & RUP008,RUP017 \\
\hline 7 & $\begin{array}{l}\text { Kesusahan pada saat } \\
\text { Login }\end{array}$ & - & \\
\hline
\end{tabular}

\section{Rekomendasi}

1. Rekomedasi pada halaman Login SIAK UNDIKSHA

\begin{tabular}{|c|c|}
\hline $\begin{array}{l}\text { SIAK Dosen } \\
\text { UNDIKSHA } \\
\text { sebelum di } \\
\text { Rekomendasi }\end{array}$ & $\begin{array}{l}\text { SIAK Dosen } \\
\text { UNDIKSHA setelah } \\
\text { di Rekomendasi }\end{array}$ \\
\hline - w Sign In & \multirow{2}{*}{ 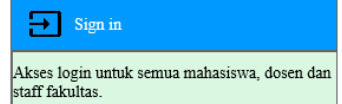 } \\
\hline 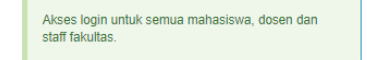 & \\
\hline $\begin{array}{c}\text { Usemame danatata Passwort yang anda } \\
\text { masulukan salah. }\end{array}$ & \multirow{4}{*}{ 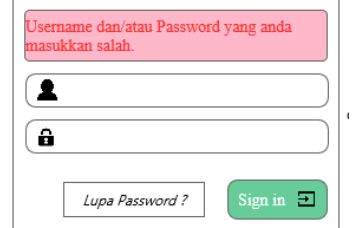 } \\
\hline$\Rightarrow 19730026200011212001$ & \\
\hline$\cdots$ & \\
\hline Sign $n$ ne & \\
\hline 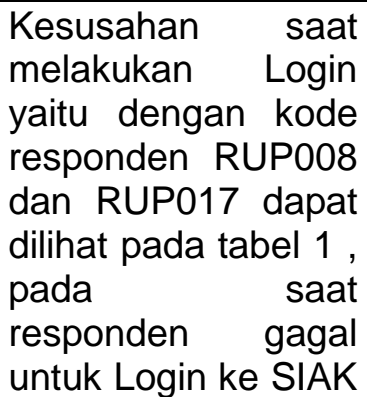 & \multirow{2}{*}{$\begin{array}{lr}\text { Perbaikan } & \text { yang } \\
\text { dilakukan } & \text { pada } \\
\text { halaman } & \text { Login } \\
\text { SIAK } & \text { Undiksha } \\
\text { yaitu memberikan } \\
\text { tombol tambahan } \\
\text { saat } \\
\text { user/responden } \\
\text { mengalami } \\
\text { kesulitan saat login } \\
\text { dengan meng-klik } \\
\text { tombil "Lupa } \\
\text { Password ?". }\end{array}$} \\
\hline $\begin{array}{l}\text { Dosen Undiksha } \\
\text { terdapat pesan yang } \\
\text { menyatakan jika } \\
\text { "Username } \\
\text { dan/atau password } \\
\text { yang anda }\end{array}$ & \\
\hline
\end{tabular}

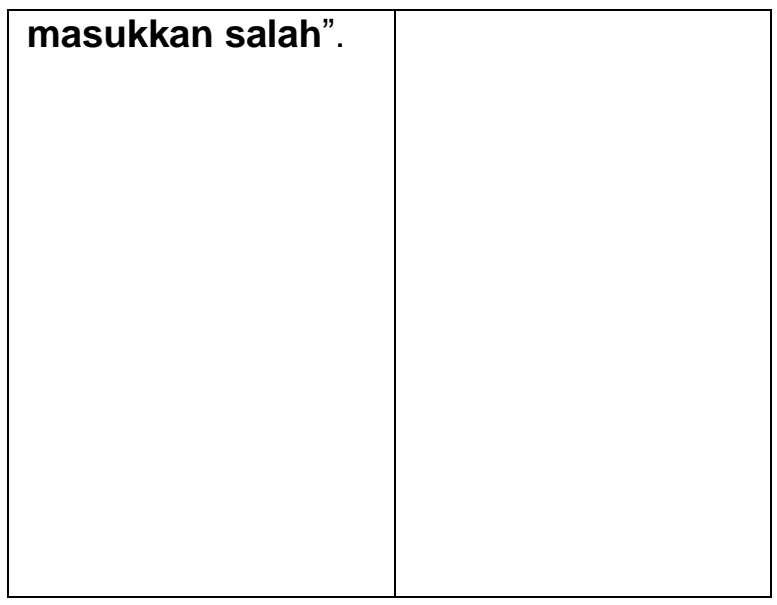

2. Rekomedasi pada perbaikan halaman Home dan Akademik.

\begin{tabular}{|c|c|}
\hline $\begin{array}{c}\text { SIAK Dosen } \\
\text { UNDIKSHA } \\
\text { sebelum di } \\
\text { Rekomendasi }\end{array}$ & $\begin{array}{c}\text { SIAK Dosen } \\
\text { UNDIKSHA setelah } \\
\text { di Rekomendasi }\end{array}$ \\
\hline & \\
\hline
\end{tabular}


Pada tabel 1 dapat dilihat kesimpulan kesulitan yang dialami oleh responden untuk mencari menu-menu yang digunakan untuk menyelesaikan tugas.
Dilakukan perbaikan pada halaman home untuk membuat responden tidak kesusahan dalam mencari menu yang berada pada menu Akademik

3. Rekomedasi Perbaikan Halaman Daftar Peserta Kuliah

\begin{tabular}{|l|l|}
\hline $\begin{array}{c}\text { SIAK Dosen } \\
\text { UNDIKSHA } \\
\text { sebelum di } \\
\text { Rekomendasi }\end{array}$ & $\begin{array}{c}\text { SIAK Dosen } \\
\text { UNDIKSHA setelah } \\
\text { di Rekomendasi }\end{array}$ \\
\hline &
\end{tabular}

4. Rekomendasi perbaikan halaman menu Agenda Mengajar Dosen.

\section{SIAK Dosen UNDIKSHA sebelum di Rekomendasi}

\section{SIAK Dosen UNDIKSHA setelah di Rekomendasi}

\begin{tabular}{|l|lr|}
\hline & \\
&
\end{tabular}

5. Rekomendasi perbaikan Halaman Jadwal.

\begin{tabular}{|l|l|}
\hline $\begin{array}{c}\text { SIAK Dosen } \\
\text { UNDIKSHA } \\
\text { sebelum di } \\
\text { Rekomendasi }\end{array}$ & $\begin{array}{c}\text { SIAK Dosen } \\
\text { UNDIKSHA setelah } \\
\text { di Rekomendasi }\end{array}$ \\
\hline &
\end{tabular}

6. Rekomendasi Perbaikan Halaman Bimbingan Mahasiswa Dan Evaluasi Akademik Dosen 


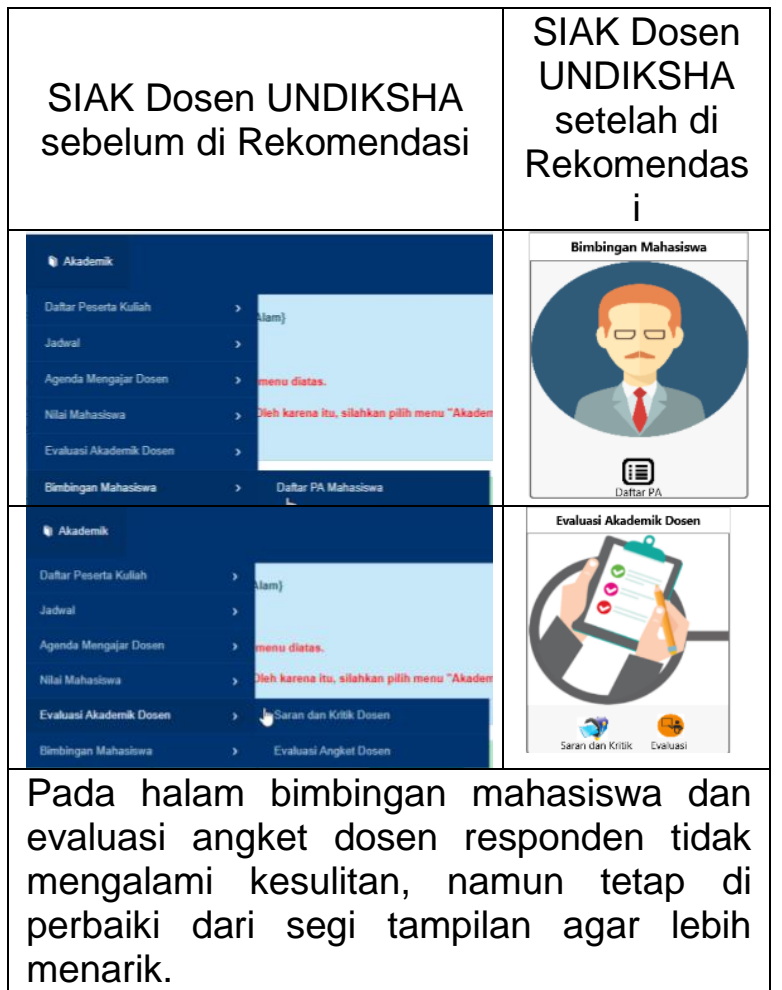

7. Rekomendasi perbaikan halaman Nilai Mahasiswa

\begin{tabular}{|c|c|}
\hline $\begin{array}{c}\text { SIAK Dosen } \\
\text { UNDIKSHA sebelum } \\
\text { di Rekomendasi }\end{array}$ & $\begin{array}{c}\text { SIAK Dosen } \\
\text { UNDIKSHA setelah } \\
\text { di Rekomendasi }\end{array}$ \\
\hline $5-$ & Nitai Mahasiswa \\
\hline$=$ & \\
\hline$=$ & \\
\hline$=$ & 9 \\
\hline $\begin{array}{l}\text { Pada tabel } 1 \text { terdapat } \\
\text { responden yang } \\
\text { mengalami } \\
\text { kesusahan yaitu } \\
\text { responden RUP001. }\end{array}$ & \begin{tabular}{|lr} 
Rekomendasi & yang \\
dilakukan & oleh \\
penulis & yaitu \\
memperbaiki & tata \\
letak pada menu \\
Nilai Mahasiswa
\end{tabular} \\
\hline
\end{tabular}

\section{SIMPULAN DAN SARAN}

Berdasarkan judul penelitian yaitu Usability Testing dengan ISO/IEC 9126-4 Sistem Informasi Akademik Universitas Pendidikan Ganesha ditinjau dari pengguna dosen yang dilakukan oleh penulis mendapatkan kesimpulan yang merujuk pada rumusan masalah dengan melakukan analisis pada 3 atribut usability sesuai dengan ISO/IEC 9126-4 yaitu

\section{Efektivitas}

Pada atribut efektivitas diperoleh hasil yaitu sistem sangat membantu responden dalam menyelesaikan tugas maka SIAK Undiksha dikatakan EFEKTIF.

\section{Efisien}

Terdapat hasil perbandingan pengerjaan waktu yang tidak signifikan dengan menggunakan perhitungan statistik Mann Whitney U Test, maka SIAK Undiksha dikatakan EFISIEN dalam membantu responden mengerjakan tugas.

3. Kepuasan pengguna.

Dengan menggunakan Kuesioner SUS untuk mengukur kepuasan pengguna dalam menyelesaikan tugas pada SIAK UNDIKSHA diperoleh hasil 77.1 yang dinyatakan sudah diatas rata-rata yaitu > 68 berarti responden PUAS menggunakan SIAK Undiksha.

4. Rekomendasi yang dilakukan yaitu sesuai dengan data yang diperoleh saat menggunakan teknik Conccurrent Thing Aloud, terdapat responden yang mengalami kesulitan pada saat menggunakan SIAK Undiksha (tabel 1), maka adapun menu yang diperbaiki sesuai dengan rekomendasi responden dan penulis yaitu ada 7 menu.

Berdasarkan pengamatan penulis terdapat beberapa hal yang dapat dijadikan bahan pertimbangan untuk ditindak lanjuti. Untuk mendapatkan nilai usability pada SIAK Undiksha penulis melakukan wawancara kepada dosen aktif Undiksha dengan tujuan mendapatkan responden pemula dan mahir serta memperoleh berbandingan waktu pengerjaan tugas oleh responden tersebut dengan menggunakan instrument yang terdapat 5 butir pernyataan. Namun pada saat pengambilan data ketika responden pemula dan mahir sudah ditentukan, ternyata instrument yang digunakan tidak terlalu berpengaruh dengan hasil yang diperoleh oleh penulis. Oleh karena itu, penulis menyarankan untuk penelitian sejenis agar mencari/menggunakan cara lain untuk menentukan instrumen yang tepat dalam penelitian. Misalnya membuat kisi-kisi soal untuk instrument yang akan di 
berikan kepada responden, kemudian dibuatkan variabel, indikator serta butir pertanyaan.Dalam menentukan teknik yang digunakan saat melakukan penelitian sejenis agar memperhatikan karakteristik responden penelitian. Saat pengambilan data penulis menggunakan teknik Conccurrent Thing Aloud (CTA), dengan menggunakan teknik tersebut seharusnya pengguna melakukan tugas Usability Testing, sesuai dengan langkah teknik CTA yaitu jika responden menemukan kesulitan pada saat mengerjakan tugas Usability Testing yang diberikan oleh penulis, maka responden harus mengucapkan keluhan atau ketidaknyamanan mereka bersamaan saat sedang mengerjakan tugas, namun yang terjadi saat pengambilan data adalah responden tidak dapat mengucapkan kesulitan dan ketidaknyaman bersamaan ketika menerjakan tugas. Responden menyampaikan kesusahan pada saat mengerjakan tugas pada saat tugas sudah selesai dikerjakan. Solusis yang sdisarankan yaitu ketika melakukan penelitian sejenis sebaiknya menggunakan teknik Restropektif Thing Aloud (RTA),karena teknik RTA sesuai dengan situasi yan telah dialami oleh penulis yaitu responden memberikan keluhan mereka pada saat tugas Usability Testing telah selesai dikerjakan.

\section{DAFTAR PUSTAKA}

9241-11:1998(en), I. (1998). Ergonomic requirements for office work with visual display terminals.

Gatsou, C., Politis, A., \& Zevgolis, D. (2013). Exploring inexperienced user performance of a mobile tablet application through usability testing., 557-564.

Krisnayani, P., Arthana, I. K. R., \& Darmawiguna, I. G. M. (2016). Analisa Usability Pada Website UNDIKSHA Dengan Menggunakan Metode Heuristic Evaluation.

Mifsud, J. (2015). Usability Metrics - A Guide To Quantify The Usability Of
Any System - Usability Geek. Retrieved from https://usabilitygeek.com/usabilitymetrics-a-guide-to-quantify-systemusability/

Pendidikan, J., Informatika, T., \& Ganesha, U. P. (n.d.). SURVEI DESKRIPTIF PENERIMAAN SISTEM INFORMASI AKADEMIK ( SIAK) PADA DOSEN UNIVERSITAS PENDIDIKAN GANESHA, (1).

Peute, L. W. P., de Keizer, N. F., \& Jaspers, M. W. M. (2015). The value of Retrospective and Concurrent Think Aloud in formative usability testing of a physician data query tool. Journal of Biomedical Informatics, 55, $1-10$.

https://doi.org/10.1016/i.jbi.2015.02.0 $\underline{06}$

Saifulloh, \& Asnawi, N. (2015). Data Manajemen dan Teknologi Informasi (DASI). Retrieved from http://ojs.amikom.ac.id/index.php/dasi

Sauro, J. (2011). MeasuringU: Mengukur Usability dengan Sistem Usability Skala (SUS).

Retrieved

from http://undiksha.ac.id/tentangundiksha/selayang-pandang/visi-danmisi/

Utama, S. (2011). Perbaikan User Interface Halaman Internet Banking dengan Metode Usability Testing. SKRIPSI.

Utami, N. W., Arthana, I. K. R. \&, \& Darmawiguna, I. G. M. (2016). Evaluasi Usability Pada E-Learning Universitas Pendidikan Ganesha dengan Metode Usability Testing. 